\title{
A ALMA HUMANA ENQUANTO PONTO CENTRAL ENIGMÁTICO ENTRE NATUREZA E ESPÍRITO ${ }^{\prime}$
}

\author{
Wolfdietrich Schmied-Kowarzik* \\ schmied-kowarzik@aon.at
}

RESUMO Tomando como ponto de partida o diálogo "Clara", escrito por Schelling, o autor faz da conexão da Natureza com o Espírito o fio condutor da trajetória do pensamento schellinguiano. É, antes de tudo, na disputa com as filosofias de Fichte e Hegel, que se revela a convergência entre a concepção transcendental do Espírito e a filosofia da Natureza, dando-se assim a entender a importância de um conceito especulativo da Natureza como acesso ao mundo real.

Palavras-chave Schelling, filosofia da Natureza, gênese do mundo, êxtase, mitologia.

ABSTRACT Taking the dialogue "Clara", written by Schelling, as a starting point, the author uses the conection of Nature with the Spirit as a guiding line for his exposition of Schelling's thought. It is, above all, the dispute with the philosophies of Fichte e Hegel that reveals the convergence between a transcendental conception of Spirit and the philosophy of Nature. Thus, the author implies the importance of speculative concept of Nature as an access to the real world.

Keywords Schelling, Philosophy of Nature, Genesis of the World, Ecstasy, Mythology.

1 Traduzido do alemão por Muriel Maia-Flickinger. Artigo recebido em 16/05/2013 e aprovado em 18/02/2014.

* Prof. aposentado da Universidade Kassel, Alemanha. 
O diálogo inacabado de Schelling, "Clara: acerca da conexão da natureza com o mundo dos espíritos" "é uma presença singular no âmbito de sua obra completa. E isso tanto no que diz respeito ao tema quanto também ao caráter do diálogo sobre o ser após a morte. Pois, diferentemente do diálogo "Bruno ou sobre o princípio divino e natural das coisas", de 1802, Schelling esforçase, aí, conscientemente, por não apresentar qualquer discussão filosófica, mantendo-se no mundo dos cidadãos cultos tanto no modo de falar quanto no universo das representações. Ao mesmo tempo, não se trata para ele de maneira alguma - apesar de todas as passagens narrativas e apesar de todas as bem-sucedidas caracterizações dos interlocutores do diálogo - da reprodução literária de uma discussão concreta, senão da mediatização ideada de posições diversamente acentuadas, que constituem todos os momentos de seu próprio pensamento. Dito de modo rude, o médico dá entrada aí enquanto advogado da natureza, do corpóreo e sensível da vida terrena, o pastor como advogado do espírito, dirigindo-se aos horizontes de sentido espiritual para além do mundo terreno, e Clara apresentando a alma medianeira, a qual enlaça um ao outro.

Até hoje não se esclareceu, de modo inequívoco, quando Schelling teria escrito o diálogo "Clara". Seu filho e primeiro editor, Karl Friedrich August Schelling, datou de 1817 a redação do mesmo, quando, em nova retrospectiva e de modo mais lúcido, Schelling voltou a ocupar-se com a morte para ele dolorosa de sua primeira mulher, Caroline. Xavier Tilliette defendeu a opinião da maioria, segundo a qual "Clara" se teria originado em 1810, imediatamente após a morte de Caroline, já que nas "Aulas privadas de Stuttgart" (1810), realizadas após, teriam sido encontradas ressonâncias temáticas do diálogo. Já Walter Ehrhardt pôde recentemente mostrar que muito diria em favor de um tempo de origem entre 1803 até 1805 , devido a que a situação inicial descrita no diálogo - através de todas as formas de estranhamento - seria bem anterior e correspondente ao luto de Caroline por sua filha Auguste Böhmer, morta em $1800 .{ }^{3}$ Concordo aqui, de modo amplo, com as exposições de Erhardt, sem entretanto querer negar serem também encontráveis traços de inserções ulteriores no Diálogo, tal como a referência à morte posterior de Clara. Não é

2 Este fragmento de um Diálogo, publicado pela primeira vez postumamente a partir dos Manuscritos de Schelling, tem até hoje apenas quatro traduções: para o francês, o italiano e o inglês e, muito recentemente, para o português, pela Editora UNIJUÍ/RS, 2012. O título em português é: "Clara: acerca da conexão da natureza com o mundo dos espíritos", com tradução, apresentação e notas de Muriel Maia-Flickinger e uma introdução do professor alemão, Wolfgang Neuser.

3 Schelling. "Prefácio do editor ao volume IX". In: Friedrich Wilhelm Joseph Schellings Sämmtliche Werke in 14 Bden. Stuttgart-Augsburg, 1856 ff. (no texto citado com o volume e a página); Tillette, 2004; Ehrhardt, 2004. 
tampouco de excluir, que, com vistas a uma possível revisão, Schelling tivesse outra vez, em 1817, lançado mão do Manuscrito. ${ }^{4}$

Justamente devido a que o escrito "Clara: acerca da conexão da natureza com o mundo dos espíritos", embora não caindo de todo fora do mundo das ideias de Schelling, encontre-se na periferia da grande linha de seu desenvolvimento filosófico, deve ser destacada em minha introdução a pergunta do filósofo quanto à conexão de natureza e espírito, que se estende enquanto motivo fundamental por todas as fases de seu pensamento. E isso inteiramente no sentido em que ele já o havia expressado em 1797, nas suas "Ideias para uma filosofia da natureza":

Pois o que é então aquele laço secreto, que liga nosso espírito com a natureza, ou aquele órgão oculto, através do qual a natureza fala ao nosso espírito ou nosso espírito à natureza?... A natureza deve ser o espírito visível, o espírito a natureza invisível. Aqui, portanto, na absoluta identidade do espírito em nós e da natureza fora de nós, tem de resolver-se o problema de como é possível uma natureza fora de nós. O fim último de nossas ulteriores investigações da natureza é por isso essa ideia da natureza. (II, $55 \mathrm{~s}$.)

\section{Os primeiros inícios}

Já em seu tempo de estudos no Seminário de Tübingen - seus dois companheiros mais velhos de quarto, Friedrich Hölderlin e Georg Wilhelm Friedrich Hegel, tinham acabado de prestar seus exames finais e deixado o Seminário - Schelling, então com 19 anos de idade, redige uma disputa com o "Timeu" de Platão, a qual só foi publicada 200 anos após seu surgimento. ${ }^{5}$ No "Timeu", segundo Schelling, Platão reflete sobre a gênese e a concatenação orgânica do mundo, não precisamente enquanto uma história mítica da criação, senão como um problema da constituição do conhecimento. Segundo Schelling, a problemática levantada não pode ser, de modo algum, filosoficamente abordada e resolvida de outra maneira, pois, se iniciada a apresentação do processo do devir a partir de um já existente, eis que se teria esquecido de esclarecer tudo o que o pensamento pressupõe, para pôr esse existente no início. Contrariamente, se iniciada a apresentação apenas com a problemática da constituição do pensamento, eis que se estaria diante do 
problema de como este conseguiria alcançar, para além de si, o processo do devir do mundo.

O que Schelling procura explicitar, portanto, é que Platão já tinha conhecimento dessas interconexões. Platão, escreve ele, concebe "o mundo inteiro como um zoon, isto é, enquanto um ser organizado" (Timeu, 33), cujos momentos constitutivos são a matéria, a forma e sua mediação. E prossegue, remetendo à "Crítica do Juízo" de Kant:

Precisamos pensar que, devido à disposição subjetiva de nossa capacidade de conhecimento, nós não podemos pura e simplesmente imaginar de modo outro a gênese de um ser organizado, a não ser através da causalidade de um conceito, de uma ideia, a qual tem de determinar tudo o que está contido no ser; precisamos pensar que, tal como as partes singulares do ser organizado produzem-se entre si umas às outras, produzindo deste modo o todo, assim, inversamente também a ideia do todo tem de ser pensada, por sua vez, enquanto precedendo e determinando a priori a forma e as partes na sua harmonia. (Timeu, 33)

No aqui expresso espelhar-se da gênese do mundo e da constituição do conhecimento, um no outro, tem-se já claramente expresso o modo como Schelling procura interpretar e resolver o problema lançado por Platão quanto à gênese do mundo no sentido da harmonia preestabelecida de Leibniz:

Quando de qualquer investigação sobre a doutrina platônica das Ideias, é preciso em geral ter diante dos olhos que Platão sempre fala sobre elas enquanto Ideias de um Intelecto divino, as quais só se tornariam possíveis através da comunidade intelectual do homem com a origem de todos os seres no seu (do homem) entendimento. (Timeu, 37)

Poucos meses ou até mesmo semanas após a redação dessa discussão com Platão, chega às mãos de Schelling o escrito de Fichte "Sobre o Conceito da Doutrina da Ciência" (1794), ${ }^{6}$ que o leva - visto superficialmente - a assumir de todo a problemática da consciência absoluta de Fichte. Desde o início, porém - como se sabe -, há diferenças significativas de sua parte em relação a Fichte, as quais se manifestam justamente no fato de Schelling ligar de antemão a problemática da constituição do conhecimento com o devir do mundo. Assim sendo, em "Do Eu como Princípio da Filosofia" (1795), desta vez a partir da perspectiva transcendental filosófica, Schelling exprime o mesmo que havia discutido um ano antes a partir do "Timeu" de Platão: 
Mas se os próprios objetos só ganham realidade através do Eu absoluto (enquanto a suma de "toda" realidade), e por isso só existem em e com o Eu empírico, eis que cada causalidade do Eu empírico é... ao mesmo tempo uma causalidade dos objetos, que devem do mesmo modo sua realidade apenas ao Eu, isto é, à suma de "toda" realidade... Logo, o último a que leva toda filosofia não é nenhum princípio objetivo, senão um princípio "imanente" de harmonia pré-estabelecida, no qual liberdade e natureza são idênticos; e este princípio nada mais é do que o Eu absoluto, do qual partiu toda filosofia. (I, 241)

\section{A filosofia transcendental}

No outono de 1798, aos 23 anos de idade - apoiado tanto por Fichte quanto por Goethe - Schelling é nomeado professor extraordinário de filosofia na Universidade de Jena, e oferece desde o início dois cursos paralelos: um sobre "Idealismo transcendental", e outro sobre "Filosofia da Natureza". O "spagat" empreendido por ele com esses dois cursos só se torna plenamente compreensível quando evidenciamos o ponto central do conflito entre Goethe e Fichte acerca do problema da natureza, conflito este que nunca se viu tematizado abertamente. Para Fichte - radicalizando Kant - a natureza se esgota de todo no seu conhecimento científico, pois não existe, para ele, nenhuma natureza em si por trás da constituição do objeto do sujeito cognitivo. Frente ao sujeito, ao Eu, a natureza é apenas Não-Eu, objeto de sua racionalidade cognitiva e determinadora de fins. Nisso justamente comprova-se a liberdade do $\mathrm{Eu}$ absoluto cognitivo e ativo frente à natureza. Comparado a isso - e por trás disso encontra-se um spinozismo naturalista - Goethe compreende a natureza como um todo vivo, ao qual, intuindo e agindo, o homem encontra-se amarrado. Daí que a sua liberdade não possa ser jamais contra a natureza, só podendo afirmar-se na conformidade racional com a mesma.

Assim concebidas, ambas as posições confrontam-se de modo inconciliável numa oposição que Schelling procurou, desde o início, superar na série dupla de seus cursos. Com o olhar retrospectivo, ele escreverá em seu "Sistema do Idealismo transcendental" (1800):

O que principalmente impulsionou o autor a aplicar-se na apresentação do contexto [...] foi o paralelismo da natureza com o inteligente, ao qual já há muito fora conduzido, e o qual não é possível nem à filosofia transcendental, nem à filosofia da natureza por si sós e separadamente apresentar de modo pleno, sendo isso possível apenas a "ambas as ciências", as quais têm de ser, ambas, justamente por isso eternamente opostas, não podendo jamais tornar-se uma. (III, 331) 
O que torna possível pensar essa convergência entre as duas ciências, Schelling o encontra dado na ideia de uma "harmonia preestabelecida", que recebe de Leibniz e desenvolve não enquanto uma harmonia preestabelecida do mundo interior e exterior, espírito e matéria, pois tal coisa seria um disparate, senão como uma "harmonia preestabelecia imanente" entre mônada individual e universo monádico. Isto é, a unidade transcendental da certeza da existência e da autoconsciência - que somos cada um de nós mesmos está em harmonia preestabelecida com a unidade de realidade e razão, que compreendemos como o dado nexo divino do mundo. Se consciência e mundo espelham-se de tal forma um no outro, tem sentido então perguntar de modo transcendental-filosófico pela sequência de níveis dos momentos constituintes da consciência, os quais formam a totalidade de nossa experiência de mundo, e, inversamente, perseguir de modo natural-filosófico a sequência de níveis das formações constitutivas que a natureza atravessa, até a produção da consciência humana. Ambos os caminhos convergentes do pensamento mostram-se então como aproximações a uma e a mesma unidade buscada, que nós, porém, nunca alcançamos inteiramente, senão sempre no salto de uma mudança de perspectiva: uma vez de modo transcendental-filosófico, a partir da imanência da consciência, e outra de modo natural-filosófico, a partir da imanência do processo da natureza. O que torna esse salto possível encontra-se entretanto em nós mesmos enquanto seres humanos, pois - como diz Schelling nas "Ideias para uma Filosofia da Natureza" (1797) - o homem é "o problema visível, o problema errante de toda a filosofia" (II, 54).

Ali onde reconstruímos de modo transcendental-filosófico, degrau por degrau, a totalidade do espírito, empreendemos na verdade o esclarecimento de nossa consciência pré-consciente, como que referindo-o à experiência da natureza. Isto quer dizer: quando chegamos à nossa autoconsciência individual, experimentando-nos enquanto existentes no mundo existente, os níveis do sentir, do intuir, da reflexão - tal como Schelling os desenvolve de modo transcendental-filosófico enquanto conteúdos da consciência - encontram-se já integrados em nossa experiência da natureza. E só a partir daqui podemos dar conscientemente início ao conhecimento científico da natureza; nessa altura porém a natureza já se encontra à nossa frente enquanto existente, nós a conhecemos estruturada de maneira espaço-temporal e vivenciamos fenômenos orgânicos. Para nossa autoconsciência individual, tudo isso se mostra enquanto uma constituição pré-consciente do horizonte absoluto de nosso espírito.

Dessa reprodução infinita de intuição e reflexão resultam, para o homem, todos os conteúdos da experiência de si mesmo e do mundo, cuja sequência de 
níveis trata-se agora de reconstruir de modo transcendental-filosófico na sua possibilitação, interpenetração e limitação mútuas. A filosofia transcendental, que percorre por inteiro esta série de níveis, mostra-se pois como a autointuição ativa do espírito no processo de seu devir através de todas suas formas; nela, o espírito intui-se enquanto existente e autocognitivo: "Todas as ações do espírito visam, portanto, representar o infinito no finito. $\mathrm{O}$ alvo de todas essas ações é a autoconsciência (do espírito), e a história dessas ações é nada outro do que a história da autoconsciência" (I, 382).

O que Schelling pré-esboça, portanto, desde o verão de 1797, enquanto história da autoconsciência do espírito, expondo-o em suas aulas de Jena, é o que virá a desdobrar em seu "Sistema do Idealismo transcendental" (1800) como reconstrução transcendental da sequência dos níveis das dimensões da experiência da natureza (sensação, intuição, reflexão), da experiência da práxis (vontade livre, direito, história), e da experiência da mediação absoluta de ambos os domínios na produtividade estética da arte.

\section{Filosofia da natureza}

Ao encontro disso vem agora, de modo correspondente, a filosofia da natureza tal como Schelling a apresenta desde 1798 nas aulas de Jena e a expõe, em 1799, em seu "Primeiro Esboço de um Sistema da Filosofia da Natureza". Aqui, vale não o experimentar, senão o reconstruir de modo refletido a própria realidade experimentada. Se quisermos conceber a natureza enquanto a própria realidade, enquanto "realidade incondicionada", entram aí - como diz Schelling - dois pressupostos: sua "autonomia" ("a natureza é sua própria legisladora"), e sua "autarquia" ("a natureza basta-se a si mesma"). Esclarecendo, o filósofo acrescenta em seu próprio exemplar das palestras de 1799: "A natureza tem sua realidade a partir de si mesma - ela é... um todo organizado a partir de si mesmo e a si mesmo organizando" (III, 17). ${ }^{7}$

Trata-se aí, portanto, da questão lançada por Kant na "Crítica do Juízo" teleológico, de como a natureza experimentada como totalidade pode ser concebida também como totalidade mediatizada a partir de si mesma. ${ }^{8}$ Só que Schelling não se detém, como Kant, apenas nessa exigência, mas tenta cumpri-la de modo concreto e diferenciado na sua filosofia da natureza: uma natureza produzindo-se a si mesma em todas as suas configurações e sempre de novo através de todas as suas formas, conservando-se e renovando-se 
através de todas as suas formas, em geral só se deixa pensar quando a fixamos em três de seus momentos, os quais constituem apenas em sua cooperação isso que experimentamos enquanto natureza real em sua concatenação processual. A natureza é, antes de tudo, produtividade infinita. Em toda parte, em que ela topa conosco, nós a experimentamos como renovando-se a si mesma de modo produtivo, tenaz e contínuo "através do que infinitamente devêm" (III, 15). Mas, só esse primeiro momento não é suficiente para abranger a natureza em sua totalidade, pois, onde quer que a experimentemos, nós o fazemos em formas determinadas. Precisamos opor à produtividade infinita um bloqueio igualmente infinito da produtividade, que age em sentido contrário enquanto segundo momento, o qual empurra à determinação e só através do qual as qualidades tornam-se em geral pensáveis (III, 24). Isso deixa-se transcrever apenas metaforicamente do seguinte modo: a partir de uma explosão inicial, uma força tende a precipitar-se para o infinito em todas as direções; e é contra a mesma que age uma força supressora contrária, de modo que em cada ponto do universo ambas vêm chocar-se com igual violência.

Tampouco esses dois momentos, porém, são suficientes para conceber a natureza real que experimentamos, porque ambos - dirigidos um contra o outro de modo igualmente forte, como posição e negação - se extinguiriam, não existisse ainda um terceiro momento que possibilitasse, em cada produto singular da mesma, sua mútua mediação. Em cada forma singular da natureza renovam-se e aniquilam-se ininterruptamente a produtividade e a reação e é isso o que experimentamos enquanto natureza. "Na natureza", escreve Schelling, "nenhum produto é portanto fixado, senão reproduzido a cada instante através da força da natureza inteira. (Nós na verdade vemos não o subsistente, senão o permanente ser reproduzidos dos produtos da natureza)" (III, 18).

Só agora alcançamos, no conceito, o que experimentamos também como natureza real e geradora, a saber, um processo produtivo que se renova permanentemente através de todas as suas configurações. Na explicação dessa ideia fundamental de como a natureza deve ser pensada enquanto devir, enquanto nexo autoprodutivo da realidade, Schelling cunha a imagem da natureza enquanto correnteza remoinhante do Devir:

Imagine-se uma correnteza [...] onde esta encontra uma resistência forma-se um redemoinho; este redemoinho não é nada de fixo, senão algo que vai desaparecendo a cada instante, a cada instante de novo se formando [...] - Em cada um de tais pontos, a correnteza se rompe (a produtividade vê-se aniquilada), mas em cada momento chega uma nova onda, que preenche a esfera. (III, 289) 
Até aqui consideramos apenas a ideia da natureza como realidade produzindo a si mesma na sua totalidade. Trata-se então agora de reconstruir, compreendendo-o, o próprio processo da natureza em suas configurações concretamente produzidas. A ideia fundamental da filosofia da natureza de Schelling é a de que os três momentos, que até agora apresentamos apenas como pressupostos do pensamento para a ideia da natureza, sejam então eles mesmos também legitimados enquanto momentos da natureza. Enquanto momentos da natureza real, porém, eles não são mais meros princípios do pensamento, senão poderes efetuadores da própria natureza, aos quais Schelling nomeia, por isso, "potências". As potências, que descrevem o conjunto da natureza na sua totalidade concreta, são a matéria, a luz e o organismo. Cada uma dessas potências, enquanto forma determinada da natureza, pode ser ela própria, por sua vez, concebida apenas através daquela acima circunscrita determinação tripla, enquanto forma autorreprodutiva, sendo que cada uma delas domina uma determinada região da mesma: a matéria domina a esfera sideral dos acontecimentos celestes, a luz domina as dimensões dinâmico-quantitativas dos processos magnéticos, elétricos e químicos e o organismo domina a região dos processos da vida.

Com as potências primárias da matéria e da luz, tal como com a da produtividade potencializada do organismo, puseram-se também em evidência, enquanto configurações próprias, os três momentos que constituem a produtividade da natureza na sua totalidade. É através de todos os três que a natureza se produz e reproduz na sua tripla produtividade infinita: como acontecimento da matéria, como processo dinâmico e como evolução orgânica, ou - como diz Schelling - o "produto da produtividade é (de cada vez) nova produtividade" (III, 324).

Mas a natureza impele ainda além, na medida em que, por seu lado, o próprio organismo leva a uma forma que não é mais forma alguma da natureza, embora se enraíze inteiramente no organismo com suas condições possibilitadoras; a saber, leva à consciência humana com sua absoluta liberdade frente à natureza. Com as potências da consciência provindas da natureza, ainda que dela totalmente independentes, isto é, com o conhecer, com o querer e o configurar começa a inteiramente nova série processual do espírito humano, a nova série processual da história. Natureza e espírito encontram-se assim, por sua vez, opostos de modo fundamentalmente excludente, sendo por isso exigida mais uma terceira dimensão mediatizadora. Para o Schelling daquela primeira fase ela se encontra na produtividade artística. Só através das três dimensões da filosofia da natureza, do espírito e da arte completa-se o circuito total da filosofia da realidade. 


\section{Filosofia da identidade}

A filosofia da natureza de Schelling é, naturalmente, um disparate para Fichte, já que para este a natureza só pode aparecer enquanto Não-Eu, isto é, enquanto um objeto oposto ao sujeito cognitivo. Na talvez mais dramática troca de cartas filosóficas que possuímos, Fichte e Schelling (1799-1801) lutam com toda uma quase inimaginável força persuasiva, por levar um ao outro afinal à verdadeira compreensão da Doutrina da Ciência, respectivamente da Filosofia da Natureza, até que, no início de 1801, acontece a ruptura definitiva entre ambos. ${ }^{9}$ Esta ruptura vê-se reforçada por Hegel (que se havia mudado para Jena em 1801), o qual põe-se inteiramente a favor de Schelling, o amigo de juventude, fazendo pública a controvérsia - até então só limitada às cartas no escrito intitulado "Diferença do Sistema da Filosofia de Fichte e Schelling" (1801). ${ }^{10}$ Em 1801, Schelling e Hegel iniciam, em parte em comum em parte paralelamente, cada um por si, a construir o Sistema da Identidade, isto é, aquele sistema que se apresenta com a exigência filosófica de pensar todo existente a partir da identidade absoluta de pensar e ser, de razão e realidade. Na concreção real-filosófica, Schelling continua a pôr o peso maior na filosofia da natureza, enquanto Hegel volta-se mais fortemente à filosofia do espírito. Não são, porém, essas colocações de pontos mais importantes que levam à separação sucessiva de ambos, senão nuances na compreensão diversa da identidade absoluta de pensar e ser. Isto se evidenciará seis anos mais tarde, com a notória crítica de Hegel a Schelling no prefácio da "Fenomenologia do Espírito" (1807). Enquanto Hegel tenta, neste caso, alcançar a unidade do pensar e do ser por meio do processo do pensamento, Schelling procura demonstrar a unidade de ambos no processo da realidade.

Façamos porém, em primeiro lugar, ao menos uma caracterização sucinta da intenção da filosofia da identidade de Schelling. A filosofia da natureza havia demonstrado que nós conseguimos muito bem pensar a realidade em si, a natureza em suas potências reais; Hegel, de modo análogo, demonstrava que podemos igualmente conceber as esferas de realidade do espírito humano, por exemplo, a esfera da economia ou do Estado, a partir da lógica do ser a elas inerente. Mas, se é possível tal concepção da realidade a partir da razão, cabe então ao acesso transcendental-filosófico da exploração de nosso conhecimento da realidade apenas a função de um conduzir propedêutico à identidade de pensar e ser, razão e realidade; função esta que podemos deixar de lado assim 
que a identidade é alcançada. Naturalmente cai também fora, com isso, como o acentuam de idêntico modo Schelling e Hegel, a referência existencial de nosso pensamento à realidade, dada originalmente com o "Eu sou". O sistema da identidade absoluta não conhece mais nenhuma consciência subjetiva que aí pense, mas desenvolve a partir de si mesmo a lógica do ser, a razão da realidade; e é só na medida em que, ao pensar, somos parte dessa identidade, que podemos compreender o desenvolvimento da razão da realidade, ou, mais precisamente, que ela se pode consumar através de nós.

A tarefa que se propõem Schelling e Hegel - e à qual, entre 1801 e 1806, ambos tentam fazer justiça em sempre novos esboços de sistemas, publicados rapidamente um após o outro por Schelling, ao passo que Hegel só os apresenta em aulas - está em achar um método que permita determinar a multiplicidade do verdadeiro existente na natureza e na história, por um lado, a partir da identidade de pensar e ser, isto é, na lógica de seu próprio ser, e, por outro lado, concebendo essa multiplicidade em uma única ordem sequencial, onde cada singular provém do que lhe fica à base, de modo a que tudo apresente por fim um único nexo geral autofundador e autoexplicitador (VII, 142). ${ }^{11}$

Confiante em si mesmo, Schelling dá início, em 1801, à "Apresentação de meu Sistema da Filosofia" - texto com o qual se inicia toda essa fase da filosofia da identidade - e, após diversas tentativas, expõe mais uma vez, em 1804, o "Sistema da Filosofia no seu todo", com a inclusão do "mundo ideal e suas potências". Mas, já neste mesmo ano anunciam-se, em seu escrito "Filosofia e Religião", os primeiros graves problemas de princípios que resultam da determinação do singular e individual, problemas estes que o levam de modo crescente a mergulhar na dúvida. ${ }^{12}$

Hegel, pelo contrário, anda muito mais lentamente nas elaborações de aulas, mas de modo também mais contínuo. Só aos poucos, entre 1812-16, aparece em três volumes sua "Ciência da Lógica", e em 1817 ele apresenta em cursos, primeiro em Heidelberg e depois em Berlim, o esboço integral de seu Sistema na forma de uma "Enciclopédia das Ciências filosóficas". Justamente esses escritos sistemáticos de Hegel levam a amadurecer em Schelling a grande crítica, que é também autocrítica, a qual então mais tarde, a partir de 1821, ele profere em suas aulas de Erlangen, München e Berlim.

11 Comp. Schmied-Kowarzik, 2004.

12 A este contexto pertence também o escrito "Clara: acerca da conexão da natureza com o mundo dos espíritos". 


\section{Sobre a essência da liberdade humana}

A crítica feita, pela primeira vez abertamente, por Hegel a Schelling na "Fenomenologia do Espírito", deixou este último não apenas subjetivamente consternado, mas o atingiu justamente em uma fase de mudança radical, a qual se viu com isso acelerada. A "Fenomenologia" começa com a certeza sensível, que se vê aí "suspensa" de modo linguístico-conceptual; ela, portanto, só começa no meio da análise da consciência transcendental, a qual seis anos antes Schelling havia apresentado no seu "Sistema do Idealismo transcendental" (1800). Logo, a "Fenomenologia" insere-se ali onde os sujeitos já se encontram frente aos fenômenos sensivelmente experimentados, entrando agora no processo da objetivação de sua determinação linguística. Vê-se com isso suprimida toda experiência pré-consciente da realidade e da natureza, na qual Schelling havia colocado tanto acento. E falta, assim, naturalmente também o horizonte de uma possível aliança de natureza e história. A "Fenomenologia do Espírito" finaliza, pelo contrário, com o autossacrifício da consciência dentro do saber absoluto da filosofia da identidade. Hegel desvia assim - aos olhos de Schelling - a referência natural-filosófica à realidade, aportando em uma filosofia que chegaria a ultrapassar Fichte na sobreculminância de um espírito posto de modo absoluto.

Schelling responde então a essa monstruosa traição e recaída de seu amigo Hegel, com o escrito "Investigações filosóficas sobre a essência da liberdade humana" (1809), último trabalho fundamental que ele ainda publica. O problema principal agora discutido por Schelling - que aqui só deverá ser mencionado em sua "pointe" contra Fichte e Hegel - é o de que a consciência humana ou o pensamento, ainda que sendo parte da produtividade real da natureza enquanto forma produzida de modo determinado, é, na verdade, tão livre e independente da concatenação real de mediação do processo da natureza, que pode até mesmo imaginar poder ser absolutamente livre e exclusivamente a partir de si mesmo. Isto é, a consciência ou o pensamento pode cair na ilusão de crer que somente ele mesmo seria real, já que só ele constituiria a partir de si mesmo a realidade objetiva, só ele, a partir da própria perfeição moral-prática, poderia fazer uso do Não-Eu enquanto material de sua própria autorrealização, sendo enfim responsável apenas perante si mesmo. A consciência autocrática e o pensamento - que de tal modo renega a sua proveniência enquanto criatura, renega o nexo irrevogável de seu ser criatura para com a natureza e sua responsabilidade para com a mesma - virão, no entanto, a se autoaniquilar justamente neste seu aferrar-se a si mesmo: 
Daqui gera-se a fome do egoísmo, o qual, na medida em que abjura o todo e a unidade, torna-se sempre mais mesquinho, mais pobre, mas justamente por isso mais ávido, mais esfomeado, mais venenoso. No mal está a contradição autodevoradora e sempre destrutiva de que anseie por tornar-se criatura justamente no instante em que destrói o laço da criaturidade e que, pela arrogância de ser tudo, caia no Não-ser (VII, 390 s.)

Schelling não quer, com isso, de maneira alguma colocar em questão a nossa liberdade humana; quer antes indicar que ela consiste justamente nessa decisão para o bem e o mal: ela se pode decidir pelo mal, isto é, pelo egoísmo da suposta liberdade da arbitrariedade e da autocracia do homem, de querer ser só a partir de si mesmo. Mas ela pode também decidir-se pelo bem, e - sem abdicar de si enquanto liberdade - compreender-se a partir do todo da natureza e saber-se corresponsável por ele. ${ }^{13}$ A liberdade humana precisa indiscutivelmente desfazer os laços com qualquer dependência imediata da natureza, porque só assim ela pode afirmar-se enquanto forma ideal do agir humano consciente livre. Isto não implica, entretanto, em que o homem deva desembaraçar-se de sua proveniência da natureza, de sua ligação viva constante com a natureza, tal como de suas tarefas em relação à natureza. Pelo contrário, a grandeza da liberdade humana consiste justamente em que ela se pode afirmar - enquanto liberdade - em harmonia com a natureza; e isso não por necessidade, senão a partir da liberdade.

\section{As idades do mundo}

Nos anos seguintes Schelling e Hegel trabalham nos fundamentos de seu pensamento subsequente, sem saber dos esforços um do outro nesse sentido. Hegel prossegue com sua "Ciência da Lógica", que, como dito, aparece em três volumes, entre 1812-16; Schelling escreve suas "Idades do Mundo", cujos esboços existem em três exemplares (1811-13), dos quais nenhum é, entretanto, publicado. ${ }^{14}$ Enquanto Hegel procura desdobrar, na dialética do processo do pensar, os fundamentos de seu sistema da Identidade, a saber, na "Lógica" na qual, falando da perspectiva de Schelling, torna-se definitivamente claro que Hegel identifica o processo do pensar (através do qual o pensamento compreende a realidade, concebendo-a) com o processo do ser, no qual o ser se configura e desdobra - logo, enquanto Hegel expõe os fundamentos dialéticos de seu sistema absoluto, Schelling, em seus esboços das "Idades

13 Para as implicações aí contidas com relação ao nosso debate atual acerca da filosofia da natureza tendo em vista a crise ecológica, comparar com Schmied-Kowarzik, 1981.

14 Schelling, 1946. 
do Mundo", rompe definitivamente e por motivos exatamente opostos com a filosofia da identidade. E ele o faz, porque, para ele, a incompatibilidade da construção absoluta do sistema e do processo da realidade torna-se clara no problema do tempo. ${ }^{15}$

O tempo foi, desde sempre, um problema central da filosofia de Schelling: o tempo vivo, próprio da consciência, e o tempo enquanto determinação do processo do devir da natureza. Agora, porém, faz-se-lhe claro - devido especialmente a ponderações autocríticas frente à forma estrutural dos esforços por ele mesmo empreendidos na sua filosofia da identidade - que ele pode muito bem dar uma determinação essencial quanto ao significado do tempo em relação ao processo da realidade, mas que, justamente essa determinação e apresentação realizada através da filosofia da identidade, não é ela mesma de fato compreendida temporalmente. Schelling toma afinal consciência de toda a discrepância entre a determinação da essência do real e do temporal na filosofia da identidade e o processo real e temporal, no qual nós mesmos nos encontramos.

A nós não interessa, no momento, que Schelling conceba as "Idades do Mundo" principalmente enquanto uma doutrina teológica da Trindade, na qual desdobra justamente a sua própria forma de uma dialética da realidade; a nós interessa, no momento, apenas a sua descoberta do processo real, o qual só podemos experimentar na sua real estruturação temporal sempre a partir de nossa temporalização enquanto passado, presente e futuro. Isto é, existe passado, presente e futuro unicamente em nós mesmos, conosco enquanto ponto central ou mais precisamente: em nossa decisão presente estamos em geral postos primeiro na tensão relacional de passado e futuro, a saber, naquele enquanto fundamento pressuposto de nossa existência, neste enquanto horizonte de nosso agir e aspirar, cujo alvo está sempre ausente. A experiência da realidade, enquanto experiência do tempo, passa sempre através de nós enquanto ponto central do tempo presente. Cada um carrega, deste modo, em si mesmo a sua temporalização real.

Nenhuma coisa [diz Schelling] nasce no tempo, senão em cada coisa gera-se o tempo de novo e imediatamente a partir da eternidade. E ainda que não se possa dizer de cada coisa que ela estaria no início do tempo, pode-se dizer que, em cada uma, está o início do tempo, a saber, em cada coisa igualmente o início eterno. Pois cada ser singular nasce do mesmo divórcio, através do qual gera-se o mundo; desde o início, portanto, com um próprio ponto central do tempo. (WA, 79) ${ }^{16}$ 
Esta afirmação só é inteiramente justa em relação à temporalização humana, que toma sempre de novo o seu início da decisão consciente do presente, com seu pôr de passado e futuro; e, ainda assim, todo outro ser vivo tem também sua vivência do tempo sempre a partir do próprio agora instantâneo.

No entanto, ainda que passado e futuro só se demarquem para cada um de nós a partir de nossa decisão de cada vez presente, encontramo-nos ao mesmo tempo tanto no processo social da história, quanto no processo da natureza em um contexto de realidade que de modo algum resulta de nossa consciência do tempo, senão do estarmos colocados nele enquanto sendolhe íntimos; contexto de realidade este que se volta para trás, ao passado dos inícios arcaicos - e antecipa o horizonte aberto ainda ausente do vindouro, mas sempre tendo a nós enquanto ponto central do devir da consciência, da ação e da antecipação. Só assim, do meio do tempo de nosso presente, aqui e agora, compreendemos enquanto reais os processos que nos abraçam e agem através de nós, encontrando-nos a nós mesmos enquanto agentes realmente individuais no contexto global do universo. ${ }^{17}$

Pois todo esse saber encontra-se numa permanente e ininterrupta produção, de modo que não se pode jamais tornar uma propriedade total. Ele é o processo interior repetitivo e imitativo daquele grande, monstruoso processo de toda vida, desde seu primeiro início silente até o presente, sim, até o futuro mais distante [...] Não é suficiente nem mesmo tomar teoricamente parte nele. Quem [...] não experimentar de modo prático [...] o processo de toda a vida [...] não o compreenderá jamais. (WA, 102)

\section{$\hat{E} x \operatorname{tase}$}

Em 1817, tendo em vista suas aulas de Heidelberg, Hegel publicou a "Enciclopédia das Ciências filosóficas", o esboço de seu sistema integral, no qual, após uma "Lógica" abreviada, ele apresentava também uma "Filosofia da Natureza" e uma "Filosofia do Espírito". Em se considerando de novo da perspectiva de Schelling, mostra-se sobretudo na "Filosofia da Natureza" de Hegel - o que aliás observaria Marx criticamente mais tarde, e de modo muito semelhante, em relação também à práxis social,$-{ }^{18}$ que ele procura pensar a natureza não a partir da lógica de sua processualidade, empreendendo antes

17 Também no que diz respeito a isso, mesmo que referido ao sujeito humano e não a Deus, há ressonâncias em "Clara: acerca da conexão da natureza com o mundo dos espíritos".

18 Marx, 1983 (MEW 42). 
determinar a natureza a partir da lógica do pensamento. Dito de modo mais geral, a dialética do processo do pensar, preestruturada na "Lógica" de Hegel, vê-se ou aplicada com força ao processo real ou the é enfiada por baixo, ao passo que, frente a isso, para Schelling trata-se sempre de conceber a realidade a partir de sua processualidade real.

Nas suas aulas subsequentes de Erlangen, intituladas "Sobre a natureza da Filosofia enquanto Ciência" (1821), Schelling faz com que isto pese a Hegel não enquanto um fracasso subjetivo, senão - dirigindo-se ao mesmo tempo de modo muito autocrítico contra seus próprios esforços anteriores em relação à filosofia da identidade - trata a problemática aí evidenciada enquanto uma incapacidade fundamental de toda filosofia até então.

Enquanto a filosofia quiser conceber a realidade a partir da razão, do pensamento, ela perderá a realidade enquanto real, pois, através de seu acesso construtivo, ela faz do real forçosamente um objeto, diante do qual só existe um sujeito, a saber, a razão. Ali onde persistirmos na prioridade do sujeito querente do saber, a realidade nos alcançará sempre apenas enquanto objeto. Pelo contrário, que se trate para nós da realidade enquanto real-existente, isto é, enquanto ela mesma subjetivamente-ativa, eis que precisamos primeiro pôr nosso pensamento fora de si enquanto sujeito querente do saber, para que seja em geral capaz de acolher o real em sua própria subjetividade. Voltado decididamente contra Hegel, Schelling insiste em que a filosofia não seria nenhuma "ciência demonstrativa", senão "ato livre do espírito", cujo primeiro passo seria "não um saber, senão bem antes e de modo expresso um não saber, um abrir mão de todo o saber para o homem. Enquanto ele ainda quiser saber, aquele sujeito absoluto se tornará para ele um objeto, e ele por isso não o reconhecerá em si” (IX, 228 s.).

Numa reinterpretação daquilo que ele antes exprimia como "intuição intelectual", Schelling acentua agora que a referência à existência não é nenhuma intuição imediata, mas provém de um ato do "êxtase", que é um ato livre do espírito. O êxtase é o decidido sair de si do pensamento, a fim de assim abrir-se diante do existente imprépensável como diante do realmente ativo. $^{19}$

A saber, nosso Eu é posto fora de si, isto é, fora de seu lugar. Seu lugar é aquele de ser Sujeito. Mas ele, agora, em contraposição ao Sujeito absoluto, não pode ser Sujeito, pois este não se pode comportar como Objeto. Logo, ele tem de abandonar o lugar,

19 Comp. Schmied-Kowarzik, 1996b. 
ele tem de ser posto fora de si enquanto um absolutamente não mais existente. Só nesta autorrenúncia pode abrir-se para ele o Sujeito absoluto. (IX, 229) ${ }^{20}$

Ora, com isso o pensamento não abdica de si inteiramente, senão apenas enquanto absolutamente primeiro, enquanto sujeito constituinte do conhecimento. Schelling sublinha expressamente que, após se ter primeiro posto extaticamente fora de si para conceder ao existente a real primazia, o pensamento precisa erguer-se, contudo, imediatamente outra vez, para compreender o que se mostra realmente a partir de seu ser real, e, a partir deste, compreender agora também a si mesmo. O pensamento só abdica de si, para tornar-se livre para o inteiramente outro da realidade existente, que o antecede de modo imprépensável, mas na qual ele mesmo é real. Com isto ele de modo algum renuncia de todo a si mesmo, a ponto de pura e simplesmente cessar de pensar; pelo contrário, após se ter aberto para o Sujeito absoluto do ser real, do qual ele mesmo brota, ele pode agora também erguer-se outra vez, a fim de refletir sobre o que é o real e o que é ele mesmo no real.

\section{Filosofia positiva e negativa}

Torna-se agora compreensível, a partir daqui, a diferença entre filosofia negativa e positiva, tal como Schelling a expõe a partir de 1827 nos seus cursos de Munique, nos quais ele avança também para uma fundamental crítica a Hegel. ${ }^{21}$ Toda filosofia que, partindo da razão, constrói realidade, chega sem dúvida a determinações da essência do real, nunca porém ao positivo da realidade existencial. Ela é, por isso, mera ciência da razão ou filosofia negativa; esta não é de modo algum sem sentido ou em vão, porque descobre tudo aquilo que temos necessariamente de pensar para compreender o real na sua racionalidade, seja isto o organismo vivo, a consciência humana ou o Estado. Se queremos compreender o que em si significam a temporalidade ou a historicidade, vemo-nos remetidos à ciência da razão, mas esta jamais consegue alcançar o realmente existente. Por isso, onde quer que desejemos encontrar o realmente existente, temos de avançar para a filosofia positiva, que inicia com o existente, e procura apanhá-lo a partir de seu ser real, que nos inclui - só assim nos experimentamos e a tudo o que existe conosco no tempo e na história.

20 Tanto ao conceito de êxtase, quanto também à ideia aqui explicitada de uma hermenêutica do ser, referese mais tarde Martin Heidegger, desde "Sein und Zeit" (1927), Tübingen 1963. Comp. também Heidegger, 1971.

21 Schelling (1827), X, $126 \mathrm{ff}$. 
O grande erro de Hegel está em negar essa diferença, interpretando já enquanto filosofia positiva a filosofia negativa, a ciência da razão, assim como se o processo conceptual do pensamento pudesse ser o próprio processo da realidade. "Não se pode negar a Hegel o mérito de ter muito bem compreendido a natureza meramente lógica daquela filosofia que se propôs trabalhar, prometendo levá-la à sua mais perfeita forma. Tivesse ele se detido nisso, tivesse ele realizado de modo rigoroso essa ideia, renunciando decididamente a todo positivo, eis que teria levado ao passo decisivo para a filosofia positiva. Só que, aquele recuo em direção ao mero pensamento, ao puro conceito, como se o pode achar expresso logo na primeira página da Lógica de Hegel, vinha ligado à pretensão de que o conceito seria tudo e nada deixaria fora de si" (X, 126 s.). Logo, embora Schelling preste louvor a Hegel pelo desempenho grandioso de seu pensamento na repartição austera da razão, o seu sistema é porém um caminho errado, já que declara o negativo por positivo. A partir dessa identificação errônea, acontece então de Hegel incorrer no erro de avaliação do real tanto na filosofia da natureza, quanto na filosofia do espírito.

Diante disso - segundo a interpretação de Schelling - a filosofia positiva é uma filosofia que vive o real, que vive a história e é também uma filosofia do ato livre. E o é porque se comporta frente ao existente imprépensável não enquanto filosofia que o constrói, senão enquanto uma filosofia que o vive. Ela é filosofia que vive a história, contanto que não considere o processo da realidade como algo determinável de fora, senão enquanto algo no meio do qual estamos inclusos, enquanto ponto central presente de decisão. Ela é filosofia do ato livre, porque nós só conseguimos colocar-nos frente ao existente através do ato livre do êxtase e porque, para nós, esse conhecer real de nós mesmos no contexto da realidade exige de nosso ser existencial humano uma firmeza presente de decisão, que ausculta o futuro.22 "Porém", escreve Schelling,

se vejo na filosofia o meio de cura para o estraçalhamento de nosso tempo, tenho em mente com isso naturalmente [...] uma filosofia tal, que se pode medir com a vida, que - longe de sentir-se impotente frente à vida e sua realidade monstruosa, ou de estar limitada à triste criatura da mera negação e destruição -, toma sua força à própria realidade, produzindo, por seu lado, também por isso ela mesma o efetivo e duradouro. (XIII, 11) 


\section{Filosofia da mitologia e da revelação}

Todos esses motivos para uma filosofia positiva da realidade enlaçamse agora na "Filosofia da Mitologia" e na "Filosofia da Revelação", ${ }^{23}$ que Schelling profere desde 1832 nas aulas de Munique e a seguir, a partir de 1841, naquelas de Berlim. Para ao menos fazer vislumbrar a intenção principal aí contida, excluo as considerações fundamentais em relação à trindade de Deus, nas quais Schelling expõe sua fundamentação de uma dialética da realidade. Preciso aqui também renunciar a entrar na nova "Apresentação do processo da natureza" (1843/44), que contém por certo a mais madura exposição do processo de evolução da natureza feita pelo filósofo. ${ }^{24}$

A "Filosofia da Mitologia" e a "Filosofia da Revelação" apresentam a grande e grandiosa filosofia da consciência da humanidade, de Schelling; aliás só referida de modo por assim dizer focal à "consciência que põe Deus". Trata-se aqui, para Schelling, do chegar-a-si-mesma da consciência humana na história, da liberdade humana na sua referência ao totalmente Outro: a Deus. Aqui, Filosofia da história não quer dizer narrativa do passado, senão o encontro da posição para a própria decisão, sempre de cada vez presente, com seu horizonte direcional voltado a um futuro ainda ausente e posto sob a responsabilidade humana.

Vista a partir de nossa liberdade presente, a "Filosofia da Mitologia" é de algum modo posta enquanto um pré-passado. Nela tornamos para nós presente a história natural no estado selvagem, inconsciente, do tornar-se consciente humano, a história pré-consciente em direção à liberdade da consciência. Os mundos mitológicos dos deuses e o processo teogônico, que se realiza através da história dos mitos, não são nenhuma invenção arbitrária do homem; ao contrário, expressa-se aqui um processo muito real e poderoso da consciência, necessário em sua natureza bruta, no qual as potências da consciência ainda não chegadas a si mesmas e se tornando autônomas enquanto deuses e lutas entre deuses - dominam a consciência humana. Só assim é possível compreender que o processo mitológico é um acontecimento coletivo, o qual ocupa tão completamente a consciência humana que arrasta a todas as formas possíveis de sacrifícios humanos, vinganças de sangue etc. Só em sua forma tardia, enquanto mito trabalhado na arte e em sua elaboração na tragédia, a consciência humana se debate por chegar à autoconsciência, aliás ainda inteiramente concebida na oposição trágica frente à força maior do destino. processes" (1843-44), "Wiener Jahrbuch für Philosophie XXX” (1998). 
Schelling torna isso claro na figura de Prometeu: "Prometeu é a ideia, na qual o gênero humano, após ter extraído de seu interior o mundo inteiro dos deuses, voltando-se a si mesmo tornou-se consciente de si e do próprio destino, e sentiu a desgraça da crença nos deuses" (XII, 482).

Com a "Filosofia da Revelação" penetramos no nosso presente de humana liberdade. A figura na qual se nos torna consciente essa liberdade, é - segundo Schelling - Jesus de Nazaré; nele, Deus tornou-se homem e o homem Deus. ${ }^{25}$ Não podemos, aqui, naturalmente apresentar a amplitude problemática dessa ideia, mas trata-se apenas de indicar um ponto decisivo para Schelling: em Jesus de Nazaré a consciência humana penetra na plena independência de sua liberdade, embora ela não se ponha, com isso, de modo absoluto, mas declare sua origem como Filho do Pai. Justamente através dessa confissão de Jesus de Nazaré enquanto ato de liberdade, ao confessar: não Eu sou Deus, mas o enviado do Pai, justamente aqui - segundo Schelling - Jesus torna-se Cristo. Abriu-se, entretanto, com isso, necessariamente, um terceiro horizonte: o do Espírito Santo, que é o horizonte posto para nós e ainda ausente da Unidade de Pai e Filho.

Esse tornar-se livre da consciência humana, junto à confissão simultânea de sua proveniência e destino, esse tornar-se livre da consciência para a ainda ausente reconciliação no espírito do amor, Schelling o apresenta de modo muito impressionante na parábola das três tentações de Jesus de Nazaré por Satanás, no deserto. Satanás tenta Jesus, propondo-lhe submeter-se a ele, isto é, submeter-se à teimosia exclusivista do ser homem, para torná-lo então senhor do mundo. Jesus resiste, porém, à tentação de Satanás, não trai sua proveniência e destino. Quando ele assim recusa a liberdade absoluta e a autocracia, não abre mão precisamente de sua liberdade, mas a resguarda na consciência de sua ligação originária de ser criatura no ato livre da recusa.

O Filho podia existir em exclusiva glória independentemente do Pai, ele podia [...] fora do Pai e sem o Pai, ser Deus, a saber, Senhor do ser; não, na verdade, Deus segundo a essência, senão Deus enquanto ato. Essa glória, porém, que ele podia ter independentemente do Pai, o Filho a desprezou, e nisto ele é Cristo. Essa é a ideia fundamental do cristianismo (XIV, 37)

Penetramos com isso na atualidade de nossa consciência da liberdade. Mas há de durar ainda muito, até que ela se torne realmente nossa própria liberdade. Essa é a história da sucessão de Cristo, isto é, da apropriação consciente de nossa liberdade; essa é a história do cristianismo que, para Schelling, ainda 
não está concluída. Aí está, primeiro, a velha Igreja Católica de Petrus, na qual a liberdade humana vê-se representada ainda através da unidade forçada e da autoridade da Igreja e que, nos seus momentos de esquecimento de Cristo, põe-se a si mesma de modo absoluto enquanto instituição humana, procedendo com terror bárbaro contra tudo o que a ela não se submete. Aí está, em segundo lugar, a Igreja de Paulus, reformada no protestantismo, na qual cada um, singularmente, é chamado à liberdade da sucessão; nos seus momentos de esquecimento de Cristo, ela se torna a autocracia absoluta do indivíduo humano, com todas as práticas de imposição de seus interesses perpetradas na total indiferença para com o próximo. É nesta época de despedaçamento que nós nos encontramos, mas com uma esperança e uma aspiração voltadas para frente, para uma Igreja de João, que não é mais Igreja alguma, porque sua unidade será uma comunidade solidária dos homens. Este é o próximo objetivo de uma aliança cristã, da qual Schelling esperava uma superação do despedaçamento do presente. Já em "O mais antigo programa de um Sistema”, de 1795/96, constava:

E reinará entre nós eterna unidade. Nunca mais o olhar desdenhoso, nunca mais o tremor cego do povo diante de seus sábios e sacerdotes. Aguarda-nos, só então, a formação idêntica de todas as forças tanto do indivíduo singular, quanto de todos. Mais nenhuma força será reprimida, reinando então liberdade geral e igualdade dos espíritos!. ${ }^{26}$

No entanto, essa comunidade joanina que aí se anuncia enquanto o novo é apenas o objetivo de nosso agir voltado ao futuro próximo, de modo algum o cumprimento de toda história, cujo horizonte futuro de unidade conciliada no Espírito Santo encontra-se para além de uma história, pela qual se possa ansiar. É nessa perspectiva que se fecha o círculo em direção àquilo que Schelling, tendo em vista o ser humano individual após a morte, procurou tematizar de modo dialogado em pinturas de ideias e de esperança, no texto afinal por ele mesmo nunca publicado, a saber, em "Clara: acerca da conexão da natureza com o mundo dos espíritos".

\section{Referências}

EHRHARDT, W. E. "Schellings Lehre über Fortdauer und künftiges Leben. Einige Bemerkungen zum Schluss der Vorlesung 'Einleitung in die Philosophie'”. StuttgartBad Cannstadt, 2004. 
FICHTE, J. G. “Ausgewählte Werke”. In sechs Bden. Darmstadt, 1962. Bd. I.

HEGEL, G. W. F. "Werke”. In 20 Bden. Frankfurt a.M., 1970. Bd. II.

HEIDEGGER, M. "Schellings Abhandlung über das Wesen der menschlichen Freiheit". Tübingen, 1971.

JAMME, C., SCHNEIDER, H. (ed.). "Mythologie der Vernunft. Hegels ältestes Systemprogramm des deutschen Idealismus". Frankfurt a.M., 1984.

KANT, I. "Werke”. In sechs Bden. Hg. v. Wilhelm Weischedel. Wiesbaden 1956 ff. "Kritik der Urteilskraft", Bd. V.

MARX, K. "Einleitung zu den Grundrissen der Kritik der politischen Ökonomie". In: K. Marx, F. Engels. Werke. In 42 Bdn. Berlin, 1983. (MEW 42).

ROSENZWEIG, F. "Das älteste Systemprogramm des deutschen Idealismus” (1917).

In: F. Rosenzweig. Leinere Schriften. Berlin, 1937.

SCHELLING, F. W. J. "Zur Geschichte der neueren Philosophie". Münchener Vorlesungen. (1827). X, $126 \mathrm{ff}$.

. "Prefácio do editor ao volume IX". In: Friedrich Wilhelm Joseph Schellings

Sämmtliche Werke in 14 Bden. Stuttgart-Augsburg, 1856 ff.

. "Die Weltalter. Fragmente”. Hg. v. Manfred Schröter. München, 1946.

. “Die Weltalter”. Hg. v. Manfred Schröter. München, 1966.

"Urfassung der Philosophie der Offenbarung”. 2 Bde. Hg. v. Walter E.

Ehrhardt. Hamburg, 1992.

. "Timaeus" (1794). Hg. v. Hartmut Buchner. Stuttgart-Bad Cannstatt, 1994.

SCHMIED-KOWARZIK, W. "Sinn und Existenz in der Spätphilosophie Schellings". Wien, 1963.

1981.

. "Das dialektische Verhältnis des Menschen zur Natur”. Freiburg/München,

"Vom Totalexperiment des Glaubens. Kritisches zur positiven Philosophie Schellings und Rosenzweigs". In: W. Schmied-Kowarzik. Franz Rosenzweig. Existentielles Denken und gelebte Bewährung. Freiburg/München, 1991.

. "Von der wirklichen, von der seyenden Natur - Schellings Ringen um eine Naturphilosophie in Auseinandersetzung mit Kant, Fichte und Hegel”. Stuttgart-Bad Cannstatt, 1996a.

. "Das spekulative Wissen oder die Ekstasis des Denkens". In: W. SchmiedKowarzik. Von der wirklichen, von der syenden Natur - Schellings Ringen um eine Naturphilosophie in Auseinandersetzung mit Kant, Fichte und Hegel. Stuttgart-Bad Cannstatt, 1996b.

. "Zur Konstituition des sittlichen Geistes in Hegels Jenaer Systementwürfen". In: Metaphysik und Hermeneutik. Festschrift für Hans-Georg Flickinger zum 60. Geb. Hg v. Heinz Eidam, Frank Hermenau, Draiton de Souza. Kassel, 2004.

SCHULZ, W. (Hg.). "Fichte - Schelling. Briefwechsel”. Frankfurt a.M., 1968. . "Schelling - Fichte. Briefwechel". Kommentiert und hg. v. Hartmut Traub. Neuried, 2001. 
STEINKAMP, F. “General Introduction”. In: F. W. J. Schelling. Clara or, On Nature's Connection to the Spirit World. Tradução e introdução de Fiona Steinkamp. Albany: State University Press, 2002.

TILLETTE, X. “Schelling. Biographie”. Stuttgart, 2004.

WIELAND, W. "Schellings Lehre von der Zeit. Grundlagen und Voraussetzungen der Weltalterphilosophie". Heidelberg, 1965. 